\title{
PKU bagi MIM Paremono melalui Media Boneka Horta dalam Pembelajaran Tematik Kurikulum 2013
}

\author{
Norma Dewi Shalikhah ${ }^{1}$, Ayu Faiza Algifahmy ${ }^{2}$ \\ ${ }^{1}$ Pendidikan Guru Madrasah Ibtidaiyah, ${ }^{2}$ Pendidikan Agama Islam, Fakultas Agama Islam, Universitas \\ muhammadiyah magelang \\ 1,2 normadewi@ummgl.ac.id
}

\begin{abstract}
ABSTRAK
Program Kemitraan Universitas (PKU) ini dilaksanakan di MIM Paremono berdasarkan beberapa identifikasi permasalahan seperti guru belum menggunakan media pembelajaran dalam peroses pembelajaran, kurangnya pemahaman tentang membuat media pembelajaran yang efektif dan efisien, dan belum terlihat karakter peduli lingkungan pada siswa. Kegiatan pengabdian ini memiliki beberapa tujuan yaitu 1) Meningkatkan kreativitas guru dan siswa dalam mengembangkan media pembelajaran, 2) Menerapkan ke siswa karakter peduli lingkungan. Target khusus yang ingin dicapai melalui pengabdian ini adalah 1) Melatih kreativitas guru dan siswa, 2) Membudayakan karakter peduli lingkungan, dan 3) Siswa dapat merawat tumbuhan melalui media boneka horta. Untuk mencapai tujuan tersebut, dilaksanakan dengan menggunakan metode action research. Tahapan kegiatan diawali persiapan meliputi ijin kegiatan, menyiapkan teknologi dan menyusun jadwal; pelaksanaan meliputi sosialisasi, praktek, dan pendampingan; dan penyusunan laporan. Adapun hasil dari pengabdian ini adalah karakter peduli lingkungan pada siswa mulai terlihat, dan menghasilkan media pembelajaran yang efektif berupa boneka horta dalam pembelajaran tematik tema merawat hewan dan tumbuhan sub tema merawat tumbuhan.
\end{abstract}

Kata kunci: media boneka horta, peduli lingkungan

\begin{abstract}
The service program was held at MIM Paremono based on several identification problems such as teachers not using learning media in learning processes, lack of understanding about making effective and efficient learning media, and not environment caring characters in students. This service activity has several objectives, namely 1) Increasing the creativity of teachers and students in developing learning media, 2) Applying to students the environment caring characters. The specific target to be achieved through this service are 1) Training the creativity of teachers and students, 2) Cultivating the environment caring characters, and 3) Students can treat plants through the media of horta dolls. To achieve these objectives, using the action research method. Stages of activities began with preparations included activities permit, preparing technology and arranging schedules; implementation included socialization, practice, and assistance; and preparation of reports. The results of this service are the character of environmental care in students began to appear, and produce effective learning media in the form of horta dolls in thematic learning the theme of caring for sub-theme animals and plants caring for plants.
\end{abstract}

Keywords: horta doll media, care for the environment

\section{PENDAHULUAN}

Tugas utama seorang guru akan efektif jika guru memiliki derajat profesionalitas tertentu yang tercermin dari kompetensi, kemahiran, kecakapan, atau keterampilan yang memenuhi standar mutu. Guru sebagai perencana pembelajaran salah satunya dituntut untuk mampu merancang pembelajaran dengan memanfaatkan berbagai jenis media dan sumber belajar yang sesuai. Penggunaan media pembelajaran diharapkan membantu siswa dalam memahami dan menerima proses pembelajaran yang dilakukan guru. Media pembelajaran dapat mewakili apa yang belum bisa disampaikan guru dan proses pembelajaran akan lebih efektif dan efisien. 
Proses belajar akan berlangsung secara optimal jika proses pembelajaran diawali dengan tahap enaktif yaitu tahap pembelajaran pengetahuan secara aktif, dengan menggunakan benda konkret atau situasi yang nyata, dilanjutkan dengan tahap ikonik yaitu tahap pembelajaran pengetahuan diwujudkan dalam bentu bayangan, gambar, atau diagram, dan diteruskan dengan tahap simbolik yaitu tahap pembelajaran pengetahuan yang diwujudkan dalam bentuk simbol-simbol abstrak (Indriasih, 2015). Dengan demikian, proses pembelajaran akan berlangsung optimal bila kegiatan seperti mengamati, menanya, mencoba, menganalisis, dan mengkomunikan dapat dipenuhi siswa, sehingga tercipta suasana pembelajaran yang menyenangkan.

Mitra yang ada dalam kegiatan pengabdian ini adalah Madrasah Ibtidaiyah Muhammadiyah Paremono. MIM Paremono merupakan salah satu sekolah yang berada di Dusun Tirto, Desa Paremono Kecamatan Mungkid Kabupaten Magelang. Kurikulum MIM Paremono menggunakan kurikulum 2013 dan KTSP. Penerapan kurikulum 2013 di MIM Paremono baru dilaksanakan di kelas 1, 2, 4, dan 5. Sedangkan kurikulum KTSP dilaksanakan di kelas 3 dan 6. Kurikulum 2013 mulai dilaksanakan sejak tahun ajaran 2017/2018.

Kegiatan pengabdian ini dilakukan di kelas 2 yang terintegrasi dengan pembelajaran tematik tema 6 yaitu merawat hewan dan tumbuhan, subtema 4 tentang merawat tumbuhan. Jumlah siswa di kelas 2 adalah 45 orang yaitu gabungan dari dua kelas A dan B.

Berdasarkan hasil pra observasi di MIM Paremono, kegiatan pembelajaran yang dilakukan oleh guru masih bersifat konvensional karena guru baru saja melaksanakan pembelajaran tematik kurikulum 2013, sehingga guru belum memulai untuk membuat atau mengembangkan media pembelajaran. Guru hanya menggunakan buku ajar tematik dari pemerintah dalam kegiatan pembelajaran. Selama ini sebelum diterapkannya kurikulum 2013, penilaian yang dilakukan guru masih mengedepankan aspek kognitif, sehingga kompetensi sikap dan keterampilan kurang menjadi tujuan dalam evaluasi. Selain itu, berdasarkan hasil analisis dari buku ajar tematik yang digunakan oleh guru yakni tema 6 subtema 4, belum terdapat media yang efektif dan efisien untuk mengembangkan karakter peduli lingkungan serta melatih siswa untuk merawat tumbuhan yang sesuai dengan tema. Dari beberapa temuan tersebut, dibutuhkan suatu media pembelajaran yang efektif dan efisien agar dapat mengoptimalkan seluruh aspek baik pengetahuan maupun sikap dan keterampilan siswa serta dapat menumbuhkan karakter pada siswa yaitu peduli lingkungan.

Boneka horta_(hortikultura) adalah suatu media terbuat dari serbuk gergaji kayu yang dimasukkan ke dalam kaos kaki tipis (stoking) kemudian dibentuk boneka dan jika bagian atas punggung boneka disiram setiap hari akan tumbuh rambut berupa rumput hijau. Boneka horta ini bisa menjadi alternatif media pembelajaran yang kreatif dan imajinatif untuk anak-anak. Boneka horta bervariasi bentuknya, dan sangat menarik bagi anak-anak. Anakanak akan dapat belajar merawat tumbuhan dari media tersebut sehingga akan melatih karakter peduli lingkungan pada anak. Selain itu melatih keterampilan bagi guru dalam mengembangkan media pembelajaran dan melatih kreativitas siswa.

\section{METODE KEGIATAN}

Kegiatan pengabdian masyarakat ini dilaksanakan di kelas 2 MIM Paremono Kecamatan Mungkid, Kabupaten Magelang. Metode dalam kegiatan pengabdian ini adalah action research. Metode tersebut dibagi menjadi 3 tahap yaitu persiapan, pelaksanaan, dan penyusunan laporan. Adapun rinciannya sebagai berikut:

Tahap persiapan meliputi :

a. Menyampaikan ijin kepada Kepala MIM Paremono karena akan digunakan sebagai lokasi kegiatan pengabdian pada masyarakat.

b. Menyiapkan teknologi yang akan diterapkan kepada sasaran mitra.

c. Menyusun jadwal kegiatan dan melakukan pembagian tugas di antara anggota tim sebagaimana berdasarkan kompetensi masing-masing.

Tahap pelaksanaan meliputi:

a. Sosialisasi tentang peduli dan cinta terhadap lingkungan

b. Siswa dan guru praktek pembuatan boneka horta

c. Siswa melakukan perawatan boneka horta setiap hari seperti menyirami dan merapikan tanaman yang tumbuh

d. Pendampingan dalam perawatan tumbuhan boneka horta

Tahap Penyusunan Laporan dan Publikasi, meliputi: 
a. Penyusunan laporan kemajuan, minimal 75 $\%$ selesai dalam waktu sesuai dengan jadwal yang telah ditentukan

b. Penyusunan laporan akhir beserta seluruh instrument pelaporan dilakukan setelah seluruh kegiatan pengabdian pada masyarakat ini selesai

c. Menulis artikel untuk diterbitkan di jurnal

\section{HASIL \& PEMBAHASAN}

Kegiatan pengabdiaan ini diawali dengan melakukan koordinasi dengan pihak MIM Paremono, dengan membawa surat tugas Lembaga Pengembangan Pendidikan dan Pengabdian Pada Masyarakat (LP3M) Universitas Muhamamdiyah Megalang. Pada pelaksanaannya sesuai metode yang kami gunakan dalam pengabdian ini adalah action research. Metode tersebut dibagi menjadi 3 tahap yaitu persiapan, pelaksanaan, dan penyusunan laporan dijelaskan sebagai berikut.

\section{Sosialisasi tentang Peduli dan Cinta terhadap Lingkungan}

Membudayakan

masyarakat

berkarakter peduli lingkungan dimungkinkan dapat efektif melalui pendidikan lingkungan di sekolah. Sebagai tempat belajar, sekolah memiliki peran khusus untuk bermain; sekolah dapat membantu siswa untuk memahami dampak perilaku manusia di bumi ini (Desfandi, 2015). Sehingga peran guru sangat penting untuk memberikan contoh dan sebagai model dalam mencintai lingkungan.

Syukri hamzah (2013: 43) menyatakan bahwa karakter peduli lingkungan bukanlah sepenuhnya talenta maupun instink bawaan, akan tetapi juga merupakan hasil dari suatu proses pendidikan dalam arti luas. Salah didik terhadap seorang individu bisa jadi akan menghasilkan karakter yang kurang terpuji tehadap lingkungan. Karena itu karakter yang baik haruslah dibentuk kepada setiap individu, sehingga setiap individu dapat menjiwai setiap tindakan dan perilakunya (Al-anwari, 2014). Karakter tersebut sebaiknya mulai dibentuk sejak usia dini dan secara terus-menerus agar tercipta suatu kebiasaan. Selain guru memberikan contoh, harus diawali dengan sosialisasi.

Sosialisasi tentang peduli dan cinta lingkungan dilaksanakan di kelas II A dan II B MI Muhammadiyah Paremono dengan jumlah siswa 45 anak. Sosialisasi tersebut memberikan pemahaman kepada siswa tentang cara kita bersyukur kepada Sang Pencipta yang telah memberikan kita lingkungan terbaik, cara merawat makhluk ciptaan Tuhan, dan akibat jika lingkungan tidak dijaga dan dirawat. Adapun kegiatan sosialisasi disajikan pada gambar 1 dan 2 sebagai berikut.

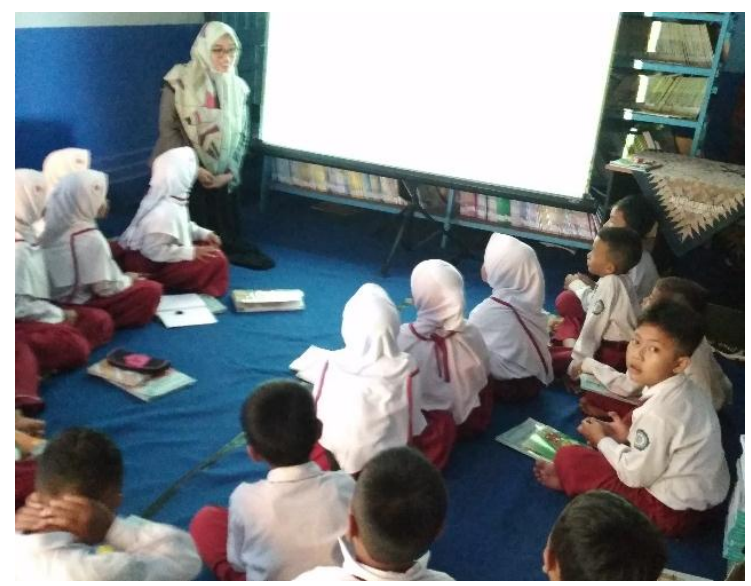

Gambar 1. Sosialisasi tentang Peduli dan Cinta terhadap Lingkungan Kelas II A

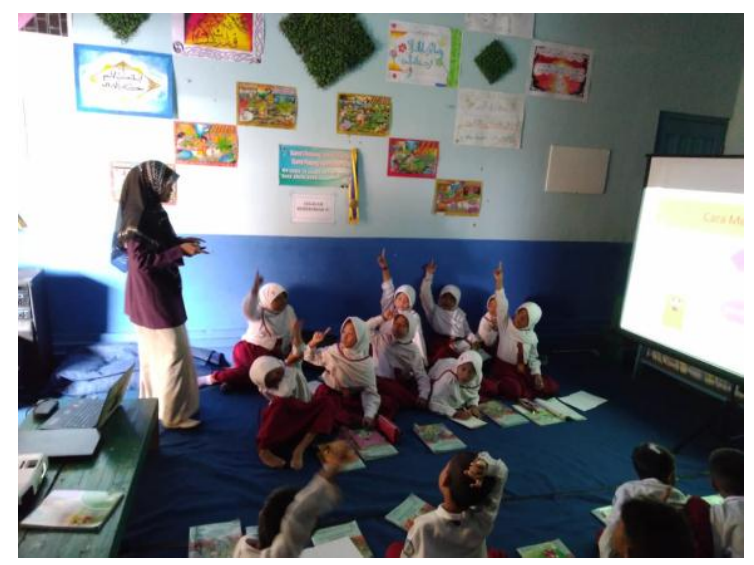

Gambar 2. Sosialisasi tentang Peduli dan Cinta terhadap Lingkungan Kelas IV B

\section{Praktek Pembuatan Boneka Horta}

Dalam kegiatan pengabdian ini, boneka horta menjadi alternatif media serta mainan edukasi untuk menerapkan karakter peduli lingkugan kepada siswa. Praktek membuat boneka horta tidak hanya dilakukan oleh siswa namun juga guru, dengan tujuan melatih keterampilan dan kreativitas siswa maupun guru dalam membuat media. Keterampilan membuat media pembelajaran merupakan hasil inovasi yang dilakukan guru dan menjadi hal yang sangat diperlukan. Inovasi tersebut dapat mengatasi permasalahan di kelas khususnya kegiatan pembelajaran yang nantinya akan ditemui calon guru SD/MI (Harini \& Usman, 2019). Permasalahan tersebut salah satunya pembelajaran kurang menarik yang menyebabkan siswa kurang bersemangat untuk belajar.

Pada kurikulum 2013 menekankan proses pendidikan yang holistik sehingga 
menyentuh pada cakupan yang lebih luas yaitu ranah kognitif, afektif, dan psikomotor. Kurikulum 2013 mengklasifikasikannya dalam empat kompetensi inti yaitu kompetensi sikap sosial, sikap spiritual, pengetahuan, dan keterampilan. Dengan demikian, maka potensi siswa selain dari domain kognitif juga dapat terpantau dan dikembangkan (Setiadi, 2016). Melalui media boneka horta, penilaian dalam kurikulum 2013 bisa mencakup semua aspek dari kognitif, keterampilan, dan sikap.

Boneka horta sebagai media yang tepat dan efektif digunakan pada pembelajaran tematik tema merawat hewan dan tumbuhan, sub tema merawat tumbuhan karena boneka horta tersebut berbentuk hewan dan akan tumbuh tanaman di bagian punggung sehingga siswa dapat langsung dengan mudah praktek merawat tumbuhan. Selain itu dengan berbagai macam bentuk hewan yang lucu, siswa akan senang merawat tumbuhan dengan demikian diharapkan terwujud budaya karakter peduli lingkungan.

Boneka horta ini terbuat dari alat dan bahan seperti serbuk gergaji kayu, bibit tanaman rumput, kaos kaki stoking, kain flannel, karet, gunting, dan lem tembak. Cara pembuatannya adalah 1) serbuk gergaji kayu yang halus dimasukkan ke dalam kaos kaki stoking beserta bibit tanaman rumput, dalam kegiatan pengabdian ini menggunakan rumput alfafa, 2) stoking diikat dengan karet agar serbuk tidak tumpah, 3) membentuk gumpalan untuk kepala, tangan, kaki, dan ekor yang kemudian diikat dengan karet, 4) lapisi karet pada gumpalan tersebut menggunakan kawat berwarna agar terlihat indah, dan 5) memberikan aksesoris berupa kain flannel pada boneka dengan ditempel menggunakan lem tembak.

Kegiatan praktek membuat boneka horta ini melatih kerampilan dan kreativitas siswa maupun guru karena dengan keterampilan masing-masing siswa dan guru dihasilkan bentuk boneka horta yang bermacam-macam. Proses pembelajaranpun menjadi menarik dan menyenangkan dibuktikan dengan antusias dan usaha siswa untuk segera menyelesaikan pembuatan boneka tersebut. Adapun pembuatan boneka horta oleh siswa dan guru disajikan pada gambar 2 dan 3 sebagai berikut.

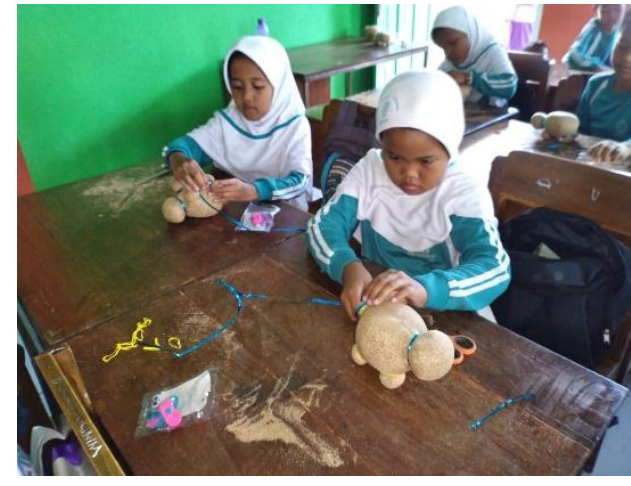

Gambar 2. Siswa Kelas II Praktek Membuat Boneka Horta

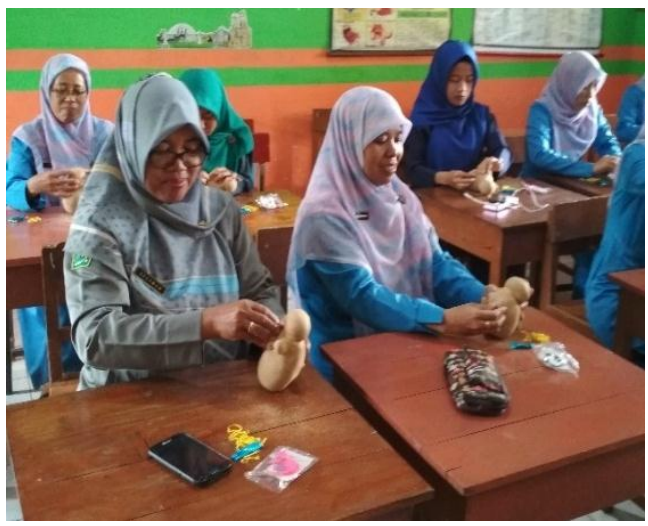

Gambar 3. Guru Praktek Membuat Boneka Horta

\section{Pendampingan Perawatan Tanaman Boneka Horta}

Pendampingan perawatan tanaman pada boneka horta ini berupa cara penyiraman dan pemangkasan tanaman yang telah menguning. Penyiraman tanaman tersebut dilakukan setiap pagi dan sore pada bagian punggung boneka agar tumbuh tanaman rumput menyerupai rambut pada hewan. Setelah tanaman rumput tumbuh panjang maka perlu dipotong untuk dirapikan dan apabila tumbuh menguning perlu untuk dipotong bagian yang menguning tersebut agar tanaman tetap tumbuh sehat. Tanaman pada boneka horta ini hanya awet tiga sampai empat bulan jika dirawat dengan baik.

Melalui media boneka horta ini, siswa mulai senang untuk merawat tumbuhan baik dari tanaman yang tumbuh di boneka horta maupun tanaman yang berada di sekitar lingkungan sekolah dan rumah siswa. Dengan demikian, dari kegiatan ini diharapkan karakter peduli lingkungan bisa diterapkan. Adapun kegiatan perawatan pada tanaman boneka horta disajikan pada gambar 4,5, dan 6 sebagai berikut. 


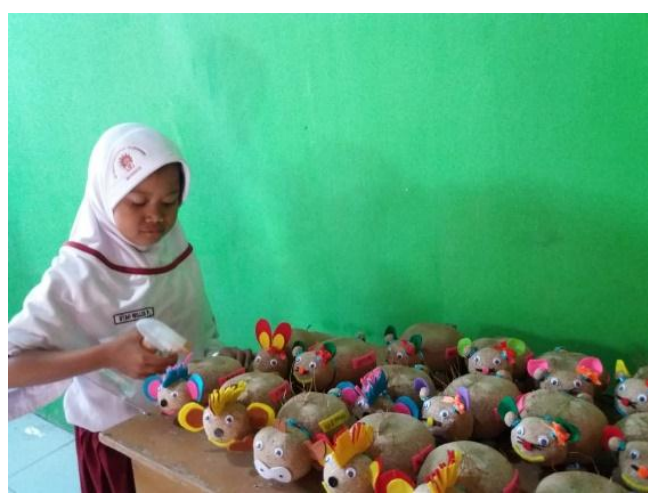

Gambar 4. Penyiraman Boneka Horta

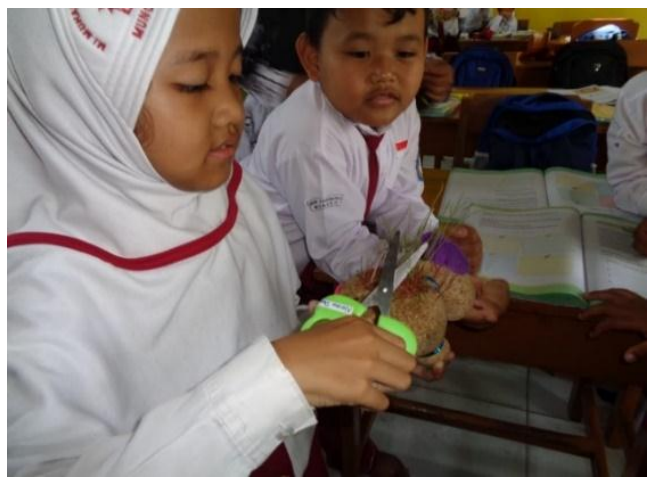

Gambar 5. Pemotongan Tanaman Boneka Horta yang Berwarna Kuning

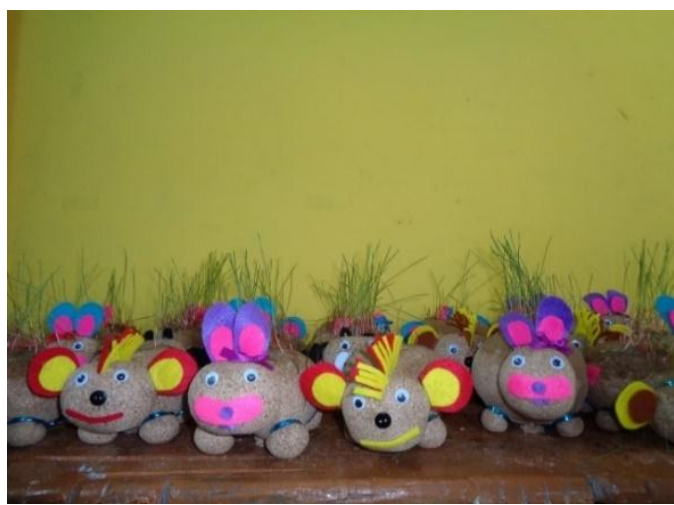

Gambar 6. Boneka Horta setelah disiram dan dipotong

\section{KESIMPULAN \& SARAN}

Adapun kesimpulan yang dapat dideskrisikan dari kegaiatan pengabdian ini adalah: 1) pemahaman dan penerapan tentang sikap peduli dan cinta lingkungan pada siswa masih rendah, dengan adanya program sosialisasi terdapat peningkatan terutama dalam merawat tumbuhan; 2) kegiatan praktek pembuatan boneka horta dapat melatih keterampilan dan kreativitas siswa maupun guru serta menjadikan proses pembelajaran di kelas menarik dan menyenangkan; 3) boneka horta menjadi media pembelajaran yang efektif dalam proses pembelajaran tematik pada tema merawat hewan dan tumbuhan sub tema merawat tumbuhan; dan 4) melalui kegiatan pendampingan perawatan tanaman boneka horta, dapat membantu siswa untuk merawat tumbuhan yang baik pada lingkungan sekolah maupun rumah. Adapun saran untuk kepala sekolah, guru, dan siswa harus menjadi teamwork untuk mewujudkan madrasah lebih baik dan memiliki karakter peduli lingkungan.

\begin{tabular}{cccr}
\hline \multicolumn{3}{c|}{ DAFTAR PUSTAKA } \\
Al-anwari, A. & M. & (2014). & Strategi \\
Pembentukan & & Karakter & Peduli \\
Lingkungan & di & Sekolah & Adiwiyata \\
Mandiri. Ta ${ }^{\prime} d i b, X I X(02), 227-252$.
\end{tabular}

Desfandi, M. (2015). Mewujudkan Masyarakat Berkarakter Peduli Lingkungan Melalui Program Adiwiyata. Sosio Didaktika, 2(1), 31-37. https://doi.org/10.15408/sd.v2i1.1661

Harini, B., \& Usman, N. (2019). Peningkatan Keterampilan Mahasiswa PGSD FKIP Universitas Sriwijaya dalam Membuat Media Pembelajaran IPS SD Berbasis Edutainment. Jurnal Publikasi Pendidikan, 9(1), 19-27.

Indriasih, A. (2015). Pemanfaatan Alat Permainan Edukatif Ular Tangga dalam Penerapan Pembelajaran Tematik di Kelas III SD. Jurnal Pendidikan, 16(2), $127-137$.

Setiadi, H. (2016). Pelaksanaan Penilaian pada Kurikulum 2013. Jurnal Penelitian Dan Evaluasi Pendidikan, 20(2), 166-178. 